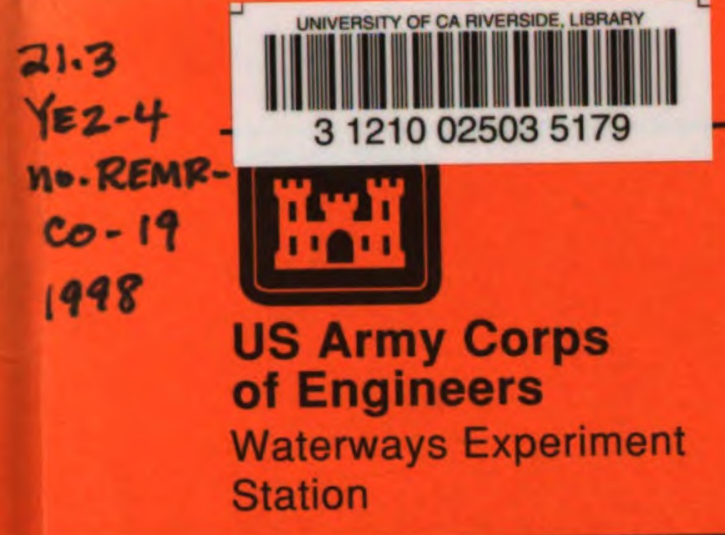

Technical Report REMR-CO-19

April 1998

Repair, Evaluation, Maintenance, and Rehabilitation Research Program

\title{
Coastal Structure Inspection Technologies
}

\section{Investigation of Multibeam Sonars for Coastal Structure Surveys}

by Terri Prickett
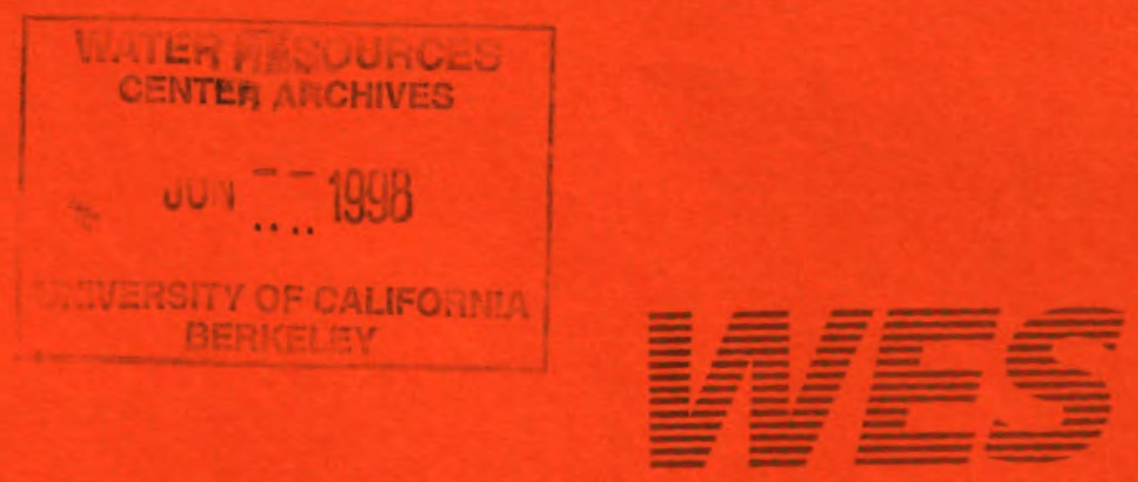

Approved For Public Release; Distribution Is Unlimited

Prepared for Headquarters, U.S. Army Corps of Engineers

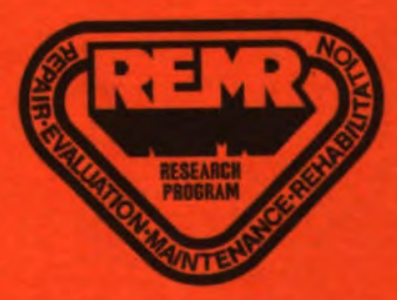

